Original Research Paper

\title{
Continuous Wavelet Transform Based Spectral Decomposition of 3d Seismic Data for Reservoir Characterization in Oyi Field, se Niger Delta
}

\author{
Chukwuemeka Ngozi Ehirim and Andifon Sylvester Akpan \\ Geophysics Research Group, Department of Physics, \\ University of Port Harcourt, P.O. Box 122, Choba, Port Harcourt, Nigeria
}

\author{
Article history \\ Received: 07-02-2017 \\ Revised: 20-04-2017 \\ Accepted: 28-04-2017 \\ Corresponding authors \\ Chukwuemeka Ngozi Ehirim \\ Geophysics Research Group, \\ Department of Physics, \\ University of Port Harcourt, \\ P.O. Box 122, Choba, Port \\ Harcourt, Nigeria \\ Email: ehirimcn@yahoo.com
}

\begin{abstract}
Continuous Wavelet Transform (CWT) is one of the most used wavelet transform based spectral decomposition methods in the direct detection of hydrocarbons and as an indicator of stratigraphic variability due to its optimal time-frequency resolution and variable time window requirements. CWT based spectral decomposition was applied on a 3D Post Stack Time Migrated (PSTM) seismic data acquired over a producing field using morlet wavelet and a time varying analysis window. Frequency amplitude slices of $10 \mathrm{~Hz}$ to $50 \mathrm{~Hz}$ were extracted from a $1625 \mathrm{~ms} \mathrm{HD} 1$ seismic horizon and analyzed for possible hydrocarbon indications and stratigraphy. Hydrocarbon filled reservoir sands were delineated as low frequency high amplitude spectral anomalies between $20 \mathrm{~Hz}$ to $30 \mathrm{~Hz}$ frequency band coincident with the locations of producing wells in the field. Also, high frequency high amplitude spectral anomaly were delineated at predominantly $50 \mathrm{~Hz}$ frequency indicating a thin-bed with probable hydrocarbon saturation particularly gas, suspected to be a bypass hydrocarbon zone. Result also shows amplitude diminution with increasing frequency attributed to local variations in lithology. Therefore, appropriate application of this method will improve reservoir characterization and enhanced bed thickness definition, de-risk prospects and minimize dry well drilling in the field.
\end{abstract}

Keywords: Continuous Wavelet Transform, Spectral Decomposition, Frequency Maps, Spectral Anomalies

\section{Introduction}

Spectral decomposition is a signal analysis technique that has proven to have the potential to selectively illuminate formations at their tuning frequencies to map bed thicknesses and detect hydrocarbon and nonhydrocarbon saturated rocks (Farfour et al., 2012). It splits/discretizes the original broad band seismic data into separate amplitude-frequency components using mathematical transform methods so that the amplitude of reflections can be examined on different component frequency one at a time (Partyka et al., 1999; Castagna et al., 2003; Liu and Marfuit, 2007). Studying the individual frequency components of the spectrum, significant insights to subtle details of the subsurface geology that hitherto not apparent in the conventional full bandwidth seismic amplitude extractions could be revealed and analyzed for possible hydrocarbon indications and stratigraphic variations.

The spectral content of seismic data is dependent on the layer thicknesses and on the dominant frequency of the wave field (Butorin, 2016). Variations in spectral content occur due to variations in bed thickness/tuning effects, attenuation/dispersion of the seismic reflection signals and changes in pore-fill, in particular the presence of gas (Partyka et al., 1999; Chapman et al., 2006; Odebeatu et al., 2006; Zhang et al., 2009). Spectral decomposition is a valuable technique that improves the clarity and resolution of reservoir seismic images. It has proved to be a robust and effective analysis tool for seismic data interpretation. They are used for mapping temporal bed thickness (Partyka et al., 1999), Hydrocarbon detection (Castagna et al., 2003; Ji-Xin et al., 2007) and stratigraphy (Peyton et al., 1998; Marfurt and Kirlin, 2001). 
The concept behind spectral decomposition in hydrocarbon exploration is that varying reservoir thicknesses tune at varying frequencies of the seismic wavelet and reflections from reservoirs are associated by attenuation of high frequency energy components of the wave field. These results in a characteristic amplitude spectral response that could be associated to varying reservoir thicknesses and hydrocarbon saturation. Therefore, by examining these spectral responses at different, discrete frequency intervals, low frequency high amplitudes responses are correlated with thick hydrocarbon saturated reservoir sands and high frequency high amplitude responses to thin-bed (channelized) reservoir sands (Mitchell et al., 1997; Sun et al., 2002; Sinha et al., 2005; Ji-Xin et al., 2007).

Different methods have been introduced for spectral decomposition of seismic data based on spectral window requirements and resolution. The wavelet transform methods and in particular, the CWT method adopted in this study uses a morlet wavelet to transform the seismic data into its component frequencies through a time varying spectral analysis window. The CWT allows seismic signal to be examined in both time-frequency domains simultaneously. It has optimal time-frequency resolution property and has become a popular tool for the spectral analysis of 3D seismic data than the windowed Fourier transform methods (Chakraborty and Okaya 1995; Castagna et al., 2003; Sinha et al., 2005).

The study area lies in Oyi field southeast of the Niger delta (Fig. 1). The field has a characteristic flat and even topography, dissected by tributary rivers with mixed mangrove and rainforest vegetation types. It is covered by thick tertiary sediments varying in age from Eocene to recent (Doust and Omatsola, 1990).

In the present study, CWT based spectral decomposition method was applied to a 3D PSTM seismic data to generate amplitude spectral attributes. These spectral attributes were subsequently, analyzed at specific frequency intervals to map stratigraphy and delineate hydrocarbon reservoirs in the field.

\section{Geologic of Oyi Field}

Oyi field is located in the Niger delta basin, southeastern Nigeria. It is an east-west trending lowrelief faulted anticline (Dagogo et al., 2016). The field is characterized by structural and stratigraphic hydrocarbon plays overlain by three stratigraphic units which are Paleocene to recent in age (Stauble and Short, 1967). These rock units are the Benin Formation at the top and the middle Agbada Formation to the north and the Akata Formation in the deep-water portion of the basin. The Benin and Agbada Formations thin and disappear seawards in the basin (Fig. 2).

The Benin Formation consists mainly of continental sand deposits with intercalation of shale and constitutes the main aquifer us unit of the basin. The producing reservoir interval is the Agbada Formation with a total thickness of about $4500 \mathrm{~m}$ and consists of unconsolidated to slightly consolidated paralic siliciclastic sequence of sandy unit with minor shale intercalations. The sand in this formation is mainly hydrocarbon reservoir with shale providing lateral and vertical seal (Weber and Daukoru, 1975; Doust and Omatsola, 1990).

The Akata Formation at the base of the Delta is of marine origin and is composed of thick shale sequences (potential source rock), turbidite sand (potential reservoirs in deep water) and minor amounts of clay and silt. The formation underlies the entire delta and is typically overpressured (Evamy et al., 1978; Doust and Omatsola, 1989).

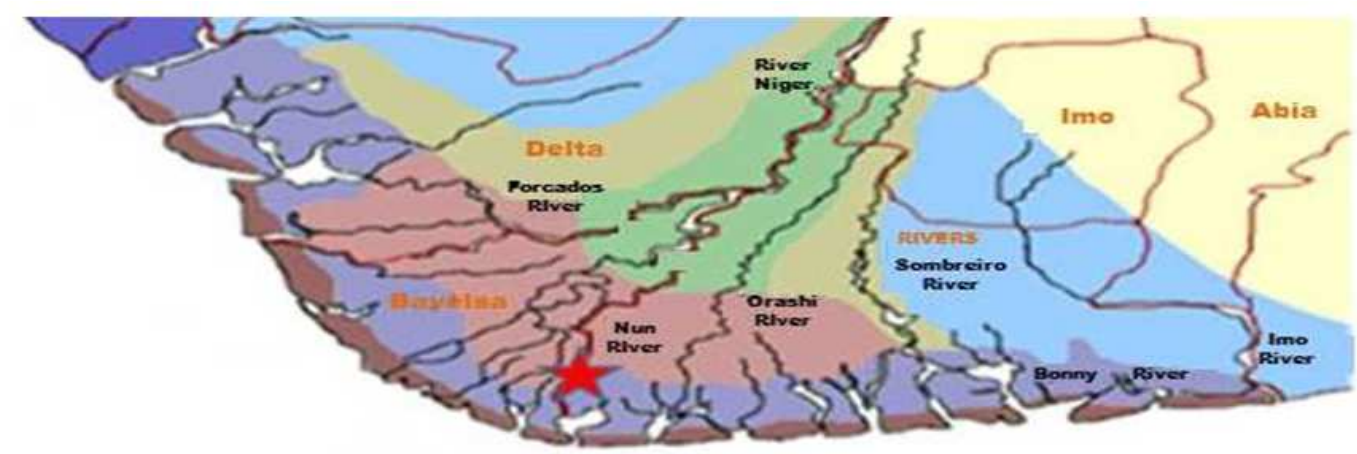

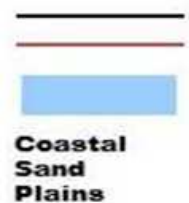
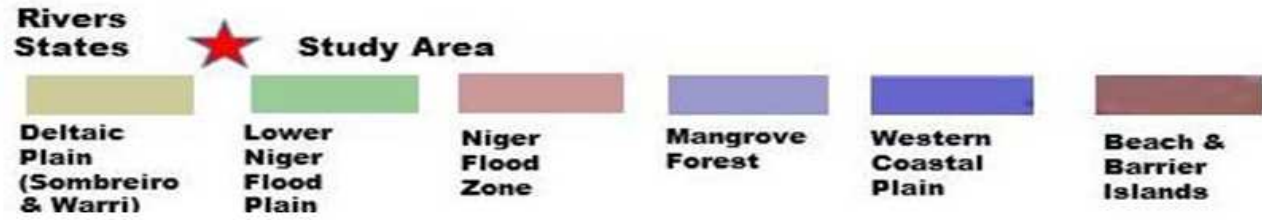

Fig. 1. Location map of Oyi field in southeastern Niger delta 


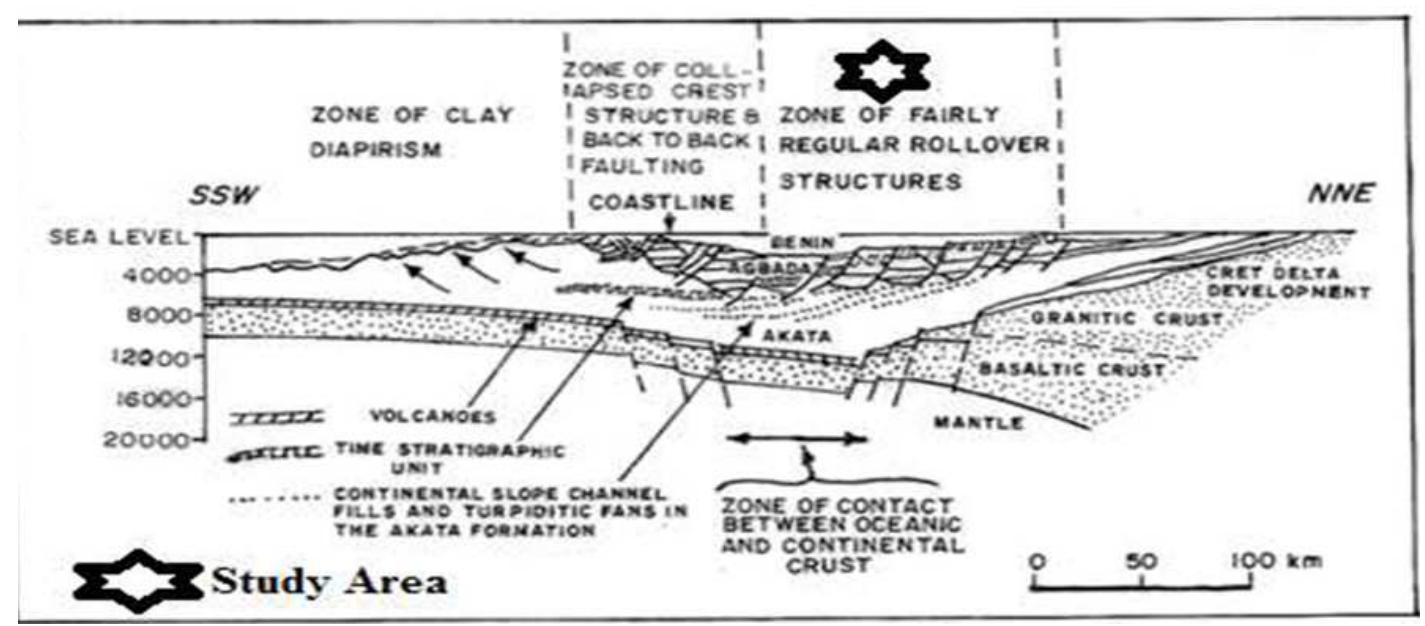

Fig. 2. Geologic and Tectonic map of Oyi field in southeastern Niger delta

\section{Materials and Methods}

\section{Methodology}

A fully processed 3D Post-Stack Time Migrated (PSTM) seismic data was used in the present study and Opendtect and Petrel software applications were used for data analysis. The 3D PSTM reflection data was analyzed for fixed inline (11669) and varying cross lines (2793-2993).

Seismic horizon HD1 marking the top of hydrocarbon sands were picked in order to aid surface attribute analysis that may provide useful geologic information using Opendtect software application. This was done by identifying continuous reflection events and picking peaks along the cross lines throughout the seismic volume. Misties arising from faulting/stratigraphy were resolved and HD1 seismic horizon was interpreted (Fig. 3).

Continuous Wavelet Transform (CWT) spectral decomposition method was implemented using Opendtect software application. This transforms the time amplitude PSTM volume to amplitude frequency volume based on morlet wavelet through a time varying analysis window on each seismic trace in the seismic volume. Furthermore, frequency attribute volumes of $10 \mathrm{~Hz}$ to $50 \mathrm{~Hz}$ were generated and loaded into Petrel software application for frequency attribute extraction.

Data slices of $10 \mathrm{~Hz}$ to $50 \mathrm{~Hz}$ frequency maps were extracted along the HD1 seismic horizon and analyzed for possible hydrocarbon indications and stratigraphy.

\section{Presentation of Results}

The frequency amplitude slices computed from a CWT based spectral decomposition of a 3D PSTM seismic data for $1625 \mathrm{~ms}$ horizon (thick yellow line) between $10 \mathrm{~Hz}$ to $50 \mathrm{~Hz}$ frequencies are shown in Fig. 4.
The frequency slices show lateral variations in amplitude distributions and varying amplitude spectra for individual frequencies. Two distinct low frequency high amplitude and high frequency high amplitude spectral anomalies were delineated to the northwest and southeast and north of the frequency slices respectively.

Result shows that to the northwest of the frequency maps, amplitudes increases with frequency between 10 $\mathrm{Hz}$ to $20 \mathrm{~Hz}$ and decreases between $20 \mathrm{~Hz}$ to $50 \mathrm{~Hz}$ frequencies. Also to the southeast of the frequency maps, the amplitude increases with frequency between $10 \mathrm{~Hz}$ to $30 \mathrm{~Hz}$ and decreases between $30 \mathrm{~Hz}$ to $50 \mathrm{~Hz}$ frequencies. However, to the north of the frequency slices above the northwest anomalous zone, amplitudes increases with frequency from $30 \mathrm{~Hz}$ and remains anomalous up to the $50 \mathrm{~Hz}$ frequency.

Analysis of result shows that the hydrocarbon reservoirs is clearly pronounced as low and high frequency high amplitude anomalies respectively, relative to the surrounding geology. Low frequency band of $20-30 \mathrm{~Hz}$ provides a better resolution and defines the thickness and boundary of the reservoir better than the higher $50 \mathrm{~Hz}$ frequency of the spectrum.

\section{Discussion of Results}

Result of the CWT based spectral decomposition of a 3D PSTM seismic data in Oyi field show spartially varying amplitude spectra for individual frequencies.

These observed spectral anomalies are due to the combined effects of thin-bed tuning and fluid-related attenuations in the reservoir rock (Castagna et al., 2003; Sinha et al., 2005). At each frequency, amplitude contrast is stronger for high hydrocarbon content and reservoir thickness. This is outstanding and well pronounced in the low than higher frequency range of the amplitude spectrum. 


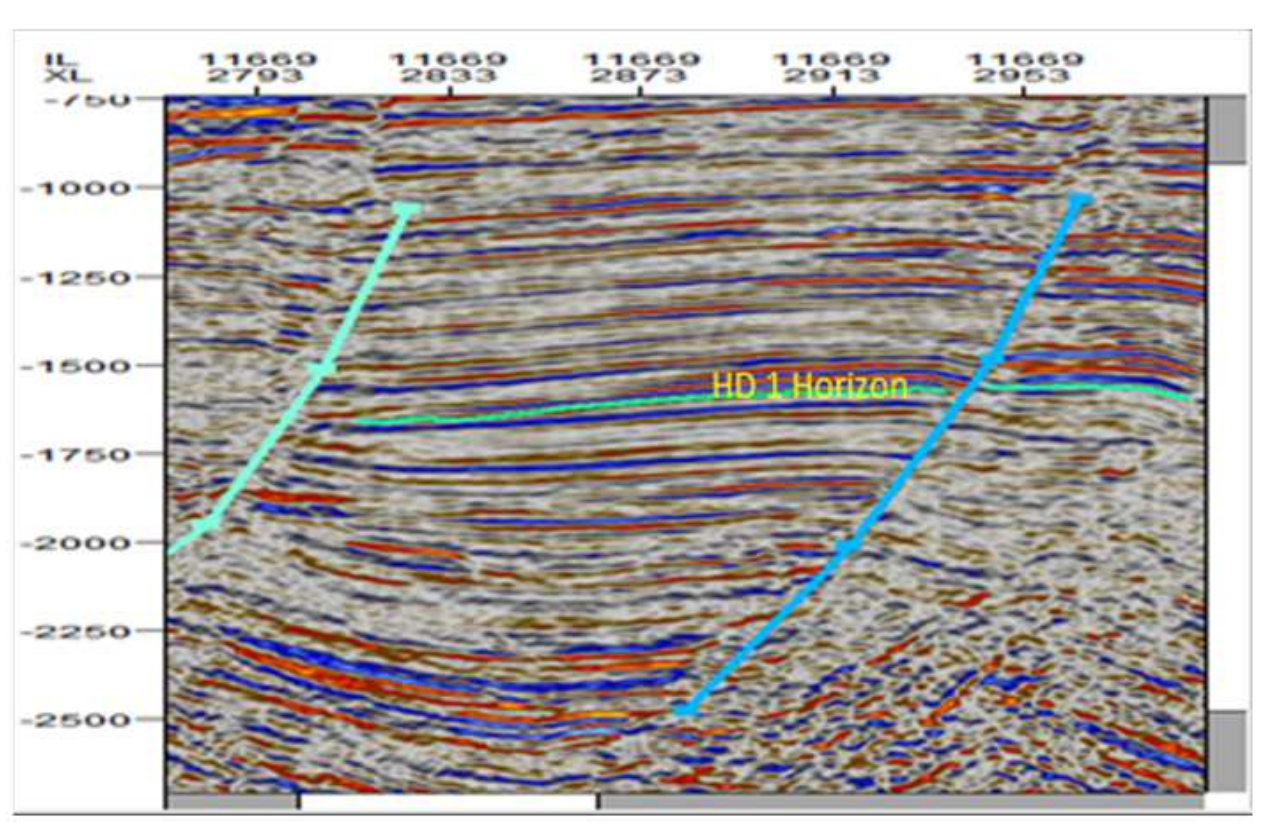

Fig. 3. Broadband PSTM seismic section across Oyi field
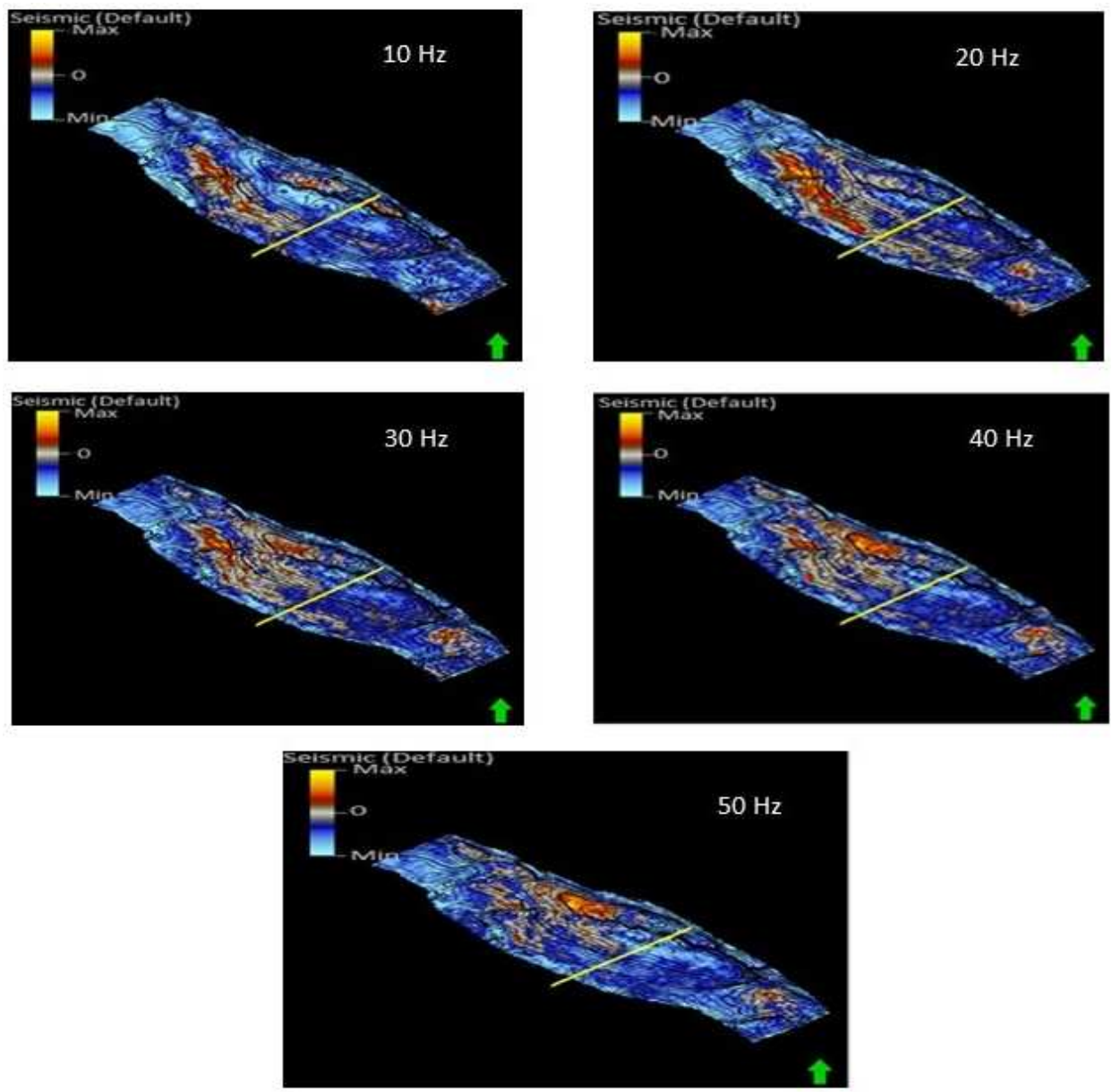

Fig. 4. Frequency amplitude slices at $10 \mathrm{~Hz}$ to $50 \mathrm{~Hz}$ frequencies on HDI seismic horizon 
Usually, the presence of hydrocarbon makes the reflectivity of the reservoir larger than those in the adjacent non-hydrocarbon filled areas (Pickford et al., 2001). Therefore, reflection of low frequency high amplitude components between $20 \mathrm{~Hz}$ to $30 \mathrm{~Hz}$ frequency band of the spectrum will delineate the target zone as thick and bright sands than at other frequencies. Consequently, hydrocarbons were clearly imaged as low frequency high amplitudes coincident with the producing zones in the field relative to the surrounding formations. This however, contrast the high frequency low amplitudes due to local variations in lithology (Partyka et al., 1999; Castagna et al., 2003).

Conversely, reflection of high frequency high amplitude components at dominantly $50 \mathrm{~Hz}$ frequency will preferentially reflect higher than lower frequencies thereby making the sand brighter and clearer. This high frequency high amplitude spectral anomaly indicate a thin-bed with probable hydrocarbon saturation, particularly gas (Partyka et al., 1999; Ji-Xin et al., 2007).

From these results, it is evident that the target zones are concentrated within the $20 \mathrm{~Hz}$ to $30 \mathrm{~Hz}$ and $50 \mathrm{~Hz}$ of the spectrum and hydrocarbons were imaged as low frequency high amplitude spectral anomalies associated with thick reservoir hydrocarbon sands and high frequency high amplitude spectral anomaly indicating a thin-bed with probable hydrocarbon saturation. This high frequency high amplitude zone do not lie within the producing zones and therefore, is suspected to be a bypass hydrocarbon zone.

\section{Conclusion}

3D post stack seismic data decomposed and sliced at various frequency ranges $(10 \mathrm{~Hz}$ to $50 \mathrm{~Hz})$ delineated hydrocarbons as low frequency high amplitude anomalies coincident with the producing zones in the field. Also, a thin-bed with probable hydrocarbon saturation particularly gas was delineated as high frequency high amplitude anomaly. This high frequency high amplitude zone do not lie within the producing zones and is suspected to be a bypass hydrocarbon zone. Analysis of result shows that the low frequency high amplitude spectral anomalies were delineated between $20 \mathrm{~Hz}$ to $30 \mathrm{~Hz}$ frequencies while the high frequency high amplitude spectral anomaly was delineated predominantly at $50 \mathrm{~Hz}$ frequency.

The present study however, has demonstrated the practical application of CWT based spectral decomposition as an effective and robust interpretation tool for improved reservoir characterization and enhanced bed thickness definition in Oyi field, southeastern Niger delta. Appropriate application of this technique will derisk prospects and minimize dry well drilling.

\section{Acknowledgment}

We would like to thank Shell Petroleum Development Company of Nigeria for providing the 3D PSTM data for the study. Our thanks also goes to the people from Opendtect.org and Schlumberger for providing the software Opendtect and Petrel for data analysis.

\section{Author's Contributions}

Chukwuemeka Ngozi Ehirim: Conception/design, analysis and interpretation of dat.

Andifon Sylvester Akpan: Processing of data, typing and revising.

\section{References}

Butorin, A.V., 2016. Application of wavelet spectral decomposition for geological interpretation of seismic data. J. Geol. Resource Eng. DOI: 10.17265/2328-2193/2016.05.004

Castagna, J.P., S. Sun and R.W. Seigfried, 2003. Instantaneous spectral analysis: Detection of lowfrequency shadows associated with hydrocarbons. Leading Edge, 22: 120-127. DOI: 10.1190/1.1559038

Chakraborty, A. and D. Okaya, 1995. Frequency-time decomposition of seismic data using waveletbased methods. Geophysics, 60: 1906-1916. DOI: $10.1190 / 1.1443922$

Chapman, M., E. Liu and X.Y. Li, 2006. The influence of fluid sensitive dispersion and attenuation on AVO analysis. Geophys. J. Int., 167: 89-105. DOI: 10.1111/j.1365-246X.2006.02919.x

Dagogo, T., C.N. Ehirim and J.O. Ebeniro, 2016. Enhanced prospect definition using well and $4 \mathrm{~d}$ seismic data in a Niger delta field. Int. J. Geosci., 7: 977-990. DOI: 10.4236/ijg.2016.78074

Doust, H. and E. Omatsola, 1990. Niger Delta: AAPG memoir 48: Tulsa. Am. Assoc. Pet. Geol.

Evamy, B.D., J. Herebourne, P. Kameling, W.A. Knap and F.A. Molley et al., 1978. Hydrocarbon habitat of tertiary Niger delta. Am. Assoc. Pet. Geol. Bull., 62: 1-39.

Farfour, M., W. Yoon and Y. Jo, 2012. Spectral decomposition in illuminating thin sand channel reservoir, Alberta, Canada. Canad. J. Pure Applied Sci., 6: 1981-1990

Ji-Xin, D., H. De-Hua, L. Jiajin and Y. Qiuliang, 2007. Application of spectral decomposition to detect deepwater gas reservoir. Proceedings of the SEG Annual Meeting, Sep. 23-28, San Antonio.

Liu, J. and K.J. Marfurt, 2007. Instantaneous spectral attributes to detect channels. Geophysics, 72: 23-31. DOI: $10.1190 / 1.2428268$ 
Marfurt, K.J. and R.L. Kirlin, 2001. Narrow-band spectral analysis and thin-bed tuning. Geophysics, 66: 1274-1283. DOI: 10.1190/1.1487075

Mitchell, J.T., N. Derzhi and E. Lickman, 1997. Low frequency shadows: The rule, or the exception? Proceeding of the SEG Annual Meeting, Nov. 2-7, Dallas, pp: 685-686.

Odebeatu, E., J. Zhang, M. Chapman, E. Liu and X.Y. Li, 2006. Application of spectral decomposition to detection of dispersion anomalies associated with gas saturation. Lead. Edge, 25: 205-210. DOI: $10.1190 / 1.2172314$

Partyka, G., J. Gridley and J. Lopez, 1999. Interpretational applications of spectral decomposition in reservoir characterization. Lead. Edge, 18, 353-360. DOI: 10.1190/1.1438295

Peyton, L., R. Bottjer and G. Partyka, 1998. Interpretation of incised valleys using new 3-D seismic techniques: A case history using spectral decomposition and coherency. Lead. Edge, 17: 1294-1298. DOI: $10.1190 / 1.1438127$

Pickford, S., A. Chavestes and B. Hill, 2001. Lithology and fluid type determination in tertiary clastic reservoirs through elastic rock properties estimation. First Break, 19: 571-574.
Sinha, S.K., P.S. Routh, P.D. Anno, C. Phillips and J.P. Castagna, 2005. Spectral decomposition of seismic data with continuous-wavelet transform. Geophysics, 70: 19-25. DOI: 10.1190/1.2127113

Stauble, A.J. and K.C. Short, 1967. Outline of geology of Niger delta. Am. Assoc. Pet. Geol. Bull. 51: 761-779.

Sun, S., J.P. Castagna and R.W. Seigfried, 2002. Examples of wavelet transform time-frequency analysis in direct hydrocarbon detection. Proceedings of the SEG Annual Meeting, Oct. 6-11, Salt Lake City.

Weber, K.J. and E.M. Daukoru, 1975. Petroleum geology of the Niger delta. Proceedings of the 9th World Petroleum Congress, May 11-16, Tokyo, pp: 210-221.

Zhang, K., KJ. Marfurt, R.M. Slatt and Y. Guo, 2009. Spectral decomposition illumination of reservoir facies. Proceedings of the 79th Annual International Meeting of Society of Exploration and Geophysics Expanded Abstract, ((AIM' 09), Houston, pp: 3515-3519. DOI: 10.1190/1.3255594 